\title{
All eyes on the Amazon
}

Meteorologist and biosphere scientist Carlos Nobre of Brazil's National Institute for Space Research in São Paulo has modelled the effects of deforestation and global warming on the Amazon. Nature talks to him about the future of the unique rainforest.

\section{Some people link deforestation with commodity prices for cattle and soya beans. Is it that simple?}

The recent decline in deforestation was driven by a very complex blend of factors. Of course, the Brazilian government may prefer to say it was law enforcement. At the same time, commodity prices in the international market for soya beans, and in the domestic market for beef, were low. In fact, all of these factors played a role, and with the reversal of this downward trend, these factors are there again. Commodity prices have gone up. But it's premature to say what is driving deforestation now, and what the impact of law enforcement will be.

\section{Which is a bigger threat: deforestation or global warming?}

That depends on the timescale. For the next 30 years, the combination of deforestation, degradation and fire is the greatest threat, but it's likely that will slow down. For the second half of the twenty-first century, global warming becomes the big, big menace. It would be too risky to gamble the future of the Amazon on the expectation that one of the models that projects a $20 \%$ increase in rainfall is correct.

\section{Is it useful to talk about 'tipping points'?}

Complex systems present this behaviour: nonlinearities, abrupt transitions, thresholds, critical points, attractors - to use the

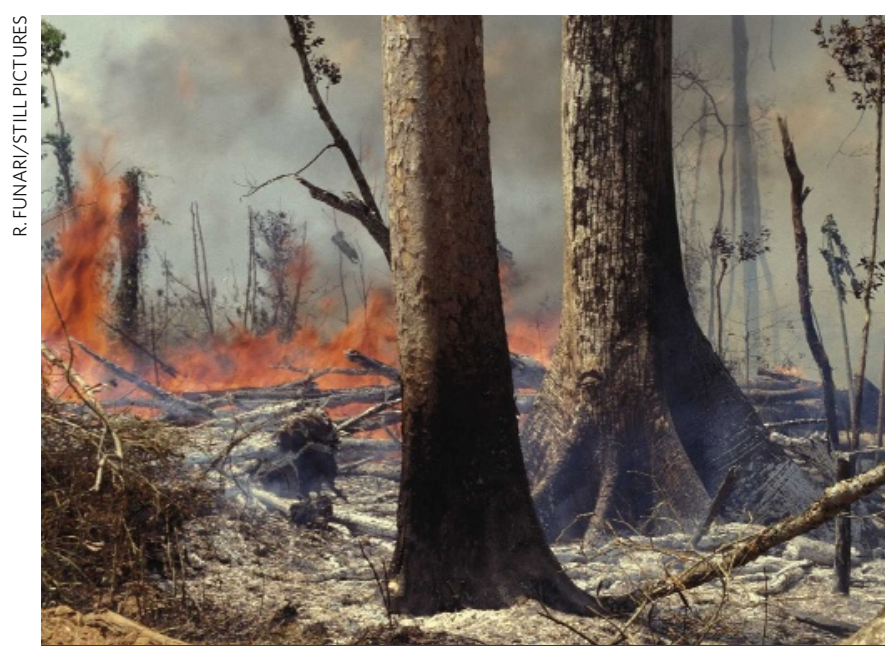

Fire is one of the biggest threats to Brazil's tropical rainforest. language of mathematics. So intellectually it's nice to frame the problem like that, because as soon as you talk to other communities that deal with complex systems, they understand you. I've seen criticism that the use of tipping points can be a scare tactic because the public understands tipping points in a different way from scientists, but I still like the concept to explain the likelihood of an abrupt change.

\section{Does the Amazon have a tipping point?}

Tropical forests exist only when there is plenty of soil moisture to transpire into the air throughout the year - less water vapour flux into the atmosphere, so less local rainfall. In our calculations, when you clear a very large chunk of forest, the climate will change and rainfall will diminish during the dry season. If the total deforested area is larger than $40-50 \%$, there is a risk of rapid savannization in the eastern to southeastern Amazon as the regional climate changes. This preliminary estimate is conservative - it does not consider fire and other forest degradation.

Another tipping point occurs with global warming. If the temperature warms more than $4^{\circ} \mathrm{C}$, there is also a risk of savannization in the east to southeast. This is mostly due to the way models handle regional differences in sea surface temperatures, which also affect the climate.

\section{What's the next big question scientists need to address in the Amazon?}

There are so many important scientific questions, but I think it's the role of humancaused fire. Fire is such a radical transformation in a tropical forest ecosystem that biodiversity loss is accelerated tremendously - by orders of magnitude. If you just do selective logging and let the area recover naturally, perhaps in 20-30 years only a botanist will be able to tell that a forest has been logged. If you

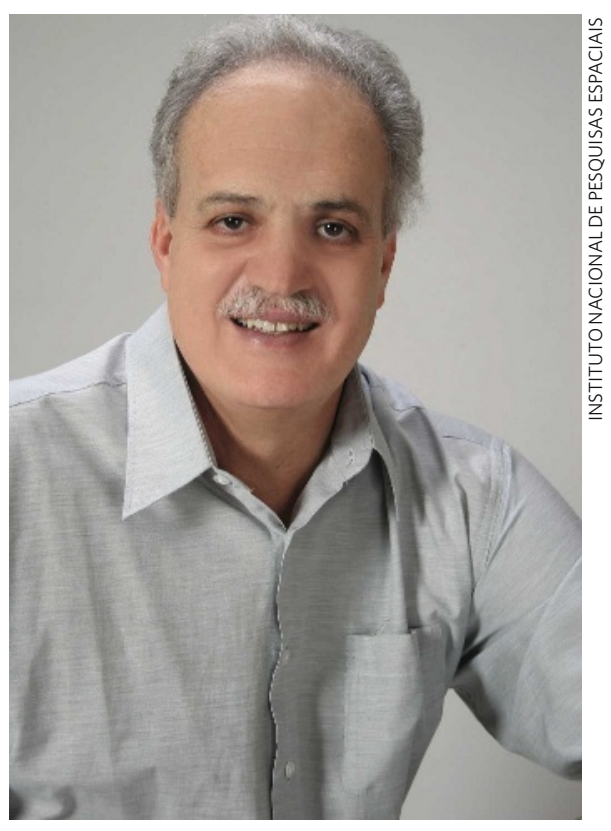

have a sequence of vegetation fires going through that area, forget it. It won't recover any more.

\section{Are you optimistic about the Amazon's future?}

If I were a politician, of course, I would have to answer 'yes'. As a scientist, I have to say no, I'm pessimistic in the short term. Everything is working against the Amazon right now. But I'm optimistic in the long run. Agriculture will become more effective. Regrowing forests and avoiding deforestation will probably be an effective answer to global warming. There is a big surge of interest in changing the economic model in the tropics, to decouple deforestation from development.

Fifty years of deforestation did not bring wealth. Selling carbon credits on the international market is not going to bring the type of money into tropical countries that would make them completely independent, wealthy countries. This is not oil. But it's a sizeable amount of money that can be used to leverage a new model of development. The fact that there will be a market will instil a sense of responsibility into tropical countries.

Interview by Jeff Tollefson 